\title{
Analisa Hemat Energi Terhadap Gedung GPIB Kelapa Gading Melalui Pendekatan OTTV
}

\author{
* Mohammad Imran \\ ${ }^{1}$ Program Studi Arsitektur, STITEK Bina Taruna Gorontalo, Indonesia \\ Alamat Email: imransains02ars_gmail@com \\ *Alamat korespondensi, Masuk: 23 Mei. 2019, Direvisi: 17 Jul. 2019, Diterima: 28 Agt. 2019
}

\begin{abstract}
ABSTRAK: OTTV (Overall Thermal Transfer Value) adalah suatu nilai yang ditetapkan sebagai kriteria perancangan untuk dinding dan kaca bagian luar bangunan Gedung yang dikondisikan meliputi tiga elemen dasar perpindahan panas yang terjadi pada selubung luar bangunan yaitu radiasi matahari melalui kaca, konduksi panas melalui dinding tak tembus cahaya dan konduksi panas melalui kaca. Lokasi penelitian adalah Gedung GPIB Kelapa Gading yang ada di Jalan Janur Asri Jakarta. Tujuan penelitian adalah untuk menganalisa hemat energi pada Bangunan GPIB Kelapa Gading dengan menggunakan pendekatan Nilai Perpindahan thermal menyeluruh atau OTTV untuk setiap bidang dinding luar bangunan dengan orientasi utara, orientasi selatan, orientasi barat dan orientasi timur. Hasil penelitian menunjukkan bahwa bangunan GPIB Kelapa Gading memiliki banyak jendela yang besar namun tidak memiliki fenetrasi sinar matahari, keseluruhan selubung bangunan jauh di atas $45 \mathrm{watt} / \mathrm{m}^{2}$. Untuk itu Bangunan GPIB Kelapa Gading perlu dikontrol ulang terhadap desain dan kenyamanan bangunannya.
\end{abstract}

Kata kunci: OTTV, Selubung bangunan, Hemat energi, Perpindahan termal, Orientasi

\begin{abstract}
OTTV (Overall Thermal Transfer Value) is a value determined as a criterion per design for the walls and glass of the building's outside which is conditioned by three basic elements related to the building's outer envelope called solar radiation through glass, heat conduction through opaque walls and heat conduction through glass. The research location is the Kelapa Gading GPIB Building on Jalan Janur Asri Jakarta. The purpose of the study was to analyze energy saving in the Kelapa Gading GPIB Building by using thermal transfer values or OTTV for each area of the building's outer wall by facilitating north, facilitating south, orienting west and allowing east. The results showed that the GPIB Kelapa Gading building had many large windows but did not have sunshine phenetration, the entire building envelope was well above 45 watts / m2. For this reason, Kelapa Gading GPIB Building needs to be re-controlled for the design and comfort of the building.
\end{abstract}

Keywords: OTTV, Building envelope, Energy saving, Thermal transfer, Orientation

\section{PENDAHULUAN}

Sesuai dengan SNI 03-6389-2000 [1], ditentukan suatu nilai untuk membatasi perolehan panas akibat dari radiasi matahari melalui selubung bangunan, yaitu OTTV $\leq 45 \mathrm{Watt} / \mathrm{m}^{2}$. Overall Thermal Transfer Value (OTTV) adalah suatu nilai yang ditetapkan sebagai kriteria perancangan untuk dinding dan kaca bagian luar bangunan gedung yang dikondisikan. Konsep OTTV meliputi 3 (tiga) elemen dasar perpindahan panas yang terjadi pada selubung luar bangunan, yaitu : 1. Radiasi matahari melalui kaca, 2. Konduksi panas melalui dinding tidak tembus cahaya dan 3 . Konduksi panas melalui kaca.

Menurut Nasional [1] Selubung bangunan merupakan elemen bangunan yang menyelubungi bangunan gedung, yaitu berupa dinding dan atap tembus atau yang tidak tembus cahaya dimana sebagian besar energi termal berpindah lewat elemen tersebut. Selubung bangunan harus memenuhi persyaratan-persyaratan yaitu (1) Berlaku hanya untuk komponen dinding dan atap pada bangunan gedung yang dikondisikan, (2) Perolehan panas akibat radiasi matahari total untuk dinding dan atap tidak boleh melebihi harga perpindahan panas menyeluruh yakni $\leq 45 \mathrm{Watt} / \mathrm{m}^{2}$.

\section{TINJAUAN PUSTAKA}

Upaya untuk mencapai bangunan hemat energi maka diperlukan kriteria konservasi energi pada selubung bangunan meliputi rasio jendela kaca terhadap dinding atau Window to Wall Ratio (WWR), jenis, tebal dan warna dinding luar, alat peneduh, konduktans kaca, insulasi atap dan 
dinding, penyerapan atap dan dinding, arah hadap, dan lain-lain [2]. Untuk memenuhi kondisi hemat dan nyaman secara visual dan termal maka perlu upaya penurunan daya, pembenahan ketidakseimbangan fasa R-S-T, perbaikan tingkat penerangan dan perbaikan kebocoran energi pengkondisian udara [3]. Penerapan konsep arsitektur sadar energi dengan mempertimbangkan perencanaan fasad bangunan khususnya pada penghawaan alami [4].

\section{BAHAN DAN METODE PENELITIAN}

Metode penelitian yang digunakan adalah kuantitatif dengan perhitungan Overall Thermal Transfer Value (OTTV) yang didasarkan SNI 036389-2000 [1]. Nilai Perpindahan Termal menyeluruh atau OTTV. Nilai perpindahan termal menyeluruh atau OTTV untuk setiap bidang dinding luar bangunan gedung dengan orientasi tertentu dapat dihitung dengan rumus berikut [5]:

$$
\begin{aligned}
\boldsymbol{O T T V}_{\boldsymbol{i}}= & \alpha\left[U_{w} x(1-W W R)\right] \times T D_{E K}+(S C x \\
& W W R \times S F)+\left(U_{f} \times W W R \times \Delta T\right)
\end{aligned}
$$

Dimana:

$$
\begin{aligned}
\mathrm{OTTV}_{\mathrm{i}}= & \begin{array}{l}
\text { harga perpindahan termal menyeluruh } \\
\text { pada dinding luar yang memiliki arah } \\
\text { atau orientasi tertentu }\left(\mathrm{Watt} / \mathrm{m}^{2}\right)
\end{array} \\
\alpha & \text { absorptansi radiasi matahari. (lihat } \\
& \text { tabel } 1 \text { dan } 2) \\
& \text { transmitansi termal dinding tidak } \\
& \text { tembus cahaya (Watt } \left./ \mathrm{m}^{2} . \mathrm{K}\right) \\
\mathrm{U}_{\mathrm{w}} & \\
\mathrm{WWR}= & \text { perbandingan luas jendela dengan luas } \\
& \text { seluruh dinding luar pada orientasi } \\
& \text { yang ditentukan } \\
\mathrm{TD}_{\mathrm{EK}}= & \text { beda temperatur ekuivalen }(\mathrm{K}) \text { (lihat } \\
& \text { tabel 3) } \\
\mathrm{SC}= & \text { koefisien peneduh dari sistem } \\
& \text { fenestrasi. } \\
\mathrm{SF}= & \text { faktor radiasi matahari (Watt } \left./ \mathrm{m}^{2}\right) \\
\mathrm{U}_{\mathrm{f}}= & \text { transmitansi termal fenestrasi } \\
& \text { (Watt } \left./ \mathrm{m}^{2} . \mathrm{K}\right) \\
\Delta \mathrm{T}= & \text { beda temperatur perencanaan antara } \\
& \text { bagian luar dan bagian dalam (diambil } \\
& 5 \mathrm{~K})
\end{aligned}
$$

Nilai perpindahan termal menyeluruh atau OTTV untuk seluruh dinding luar bangunan gedung dapat dihitung dengan rumus :

$$
\text { OTTV }=\frac{\left(A_{o 1} \times \text { oTTV }_{1}\right)+\left(A_{o 2} \times \text { oTTV }_{2}\right)+\cdots+\left(A_{o i} \times \text { oTTV }_{i}\right)}{\left(A_{o 1}+A_{o 2}+\cdots+A_{o i}\right)}
$$

\section{Dimana:}

$\mathrm{A}_{\mathrm{oi}}$ adalah luas dinding pada bagian dinding luar $i$ $\left(\mathrm{m}^{2}\right)$. Luas total ini termasuk semua permukaan dinding tidak tembus cahaya dan luas permukaan jendela yang terdapat pada bagian dinding tersebut

OTTV $_{\mathrm{i}}$ adalah harga perpindahan termal menyeluruh pada bagian dinding $i$ sebagai hasil perhitungan dengan menggunakan rumus sebelumnya $\left(\mathrm{Watt} / \mathrm{m}^{2}\right)$

Nilai absorptansi termal $(\alpha)$ untuk beberapa jenis permukaan dinding tidak tembus cahaya dapat dilihat pada tabel di bawah ini [6].

Tabel 1. Nilai Absorptansi Radiasi Matahari untuk Dinding Luar dan Atap Tidak Tembus Cahaya

\begin{tabular}{lc}
\hline \multicolumn{1}{c}{ Bahan Dinding Luar } & $\boldsymbol{\alpha}$ \\
\hline Beton berat & 0,91 \\
Bata merah & 0,89 \\
Batu sabak & 0,88 \\
Beton Ringan & 0,87 \\
Aspal Jalan Setapak & 0,86 \\
Kayu Permukaan Halus & 0,82 \\
Beton Ekspos & 0,78 \\
Ubin Putih & 0,61 \\
Bata Kuning Tua & 0,58 \\
Atap Putih & 0,56 \\
Cat Aluminium & 0,50 \\
Kerikil & 0,40 \\
Seng Putih & 0,29 \\
Batu Gelazur Putih & 0,26 \\
Lembaran Aluminium & 0,25 \\
Bangunan Nuklir & 0,12 \\
\hline
\end{tabular}

Tabel 2. Nilai Absorbtansi Radiasi Matahari untuk Cat Permukaan Dinding Luar

\begin{tabular}{lc}
\hline \multicolumn{1}{c}{ Cat Permukaan Dinding } & $\boldsymbol{\alpha}$ \\
\hline Hitam Merata & 0,95 \\
Pernis Hitam & 0,92 \\
Abu-Abu Tua & 0,91 \\
Pernis Biru Tua & 0,91 \\
Cat Minyak Hitam & 0,90 \\
Coklat Tua & 0,88 \\
Abu-Abu/Biru Tua & 0,88 \\
Biru/Hijau Tua & 0,88 \\
Coklat Medium & 0,84 \\
Pernis Hijau & 0,79 \\
Hijau Medium & 0,59 \\
Kuning Medium & 0,58 \\
Hijau/Biru Medium & 0,57 \\
Hijau Muda & 0,47 \\
Putih Semi Kilap & 0,30 \\
Putih Kilap & 0,25 \\
Perak & 0,25 \\
Pernis Putih & 0,21 \\
\hline
\end{tabular}

(Sumber: Satwiko, 2008) 
Beda temperatur ekuivalen dipengaruhi oleh beberapa faktor yaitu (1) tipe, (2) massa dan densitas konstruksi, (3) Lokasi dan orientasi bangunan, (4) Kondisi perancangan [5]. Untuk menyederhanakan perhitungan OTTV, maka nilai $\mathrm{TD}_{\mathrm{EK}}$ untuk beberapa konstruksi tercantum pada tabel berikut ini.

Faktor radiasi matahari (SF), merupakan laju rata-rata setiap jam dan radiasi matahari pada selang tertentu sampai pada suatu permukaan. Objek penelitian adalah Gedung GPIB yang terletak di Kelapa Gading Jakarta Utara, maka faktor radiasi matahari (SF) antara Pukul 07.00-18.00 adalah pada tablel dibawah ini:

Tabel 3. Nilai $k$ Bahan Bangunan

\begin{tabular}{lcc}
\hline \multicolumn{1}{c}{ Bahan Bangunan } & $\begin{array}{c}\text { Densitas } \\
\left(\mathbf{K g} / \mathbf{m}^{\mathbf{3}}\right)\end{array}$ & $\mathbf{K} \mathbf{( W / m . K )}$ \\
\hline Beton & 0,91 & 1,448 \\
Beton Ringan & 0,89 & 0,33 \\
Bata dengan Lapisan & 1760 & 0,807 \\
$\quad$ Plester & & \\
Bata langsung dipasang & & 1,154 \\
tanpa plester, tahan & & \\
terhadap cuaca & & \\
Plesteran Pasir Semen & 1568 & 0,533 \\
Kaca Lembaran & 2512 & 1,053 \\
Papan Gypsum & 880 & 0,170 \\
Kayu Lunak & 608 & 0,125 \\
Kayu Keras & 702 & 0,138 \\
Kayu Lapis & 528 & 0,148 \\
Glasswool & 32 & 0,035 \\
Fiberglass & 32 & 0,035 \\
Paduan Aluminium & 2672 & 211 \\
Tembaga & 8784 & 385 \\
Baja & 7840 & 47,6 \\
Granit & 2640 & 2,927 \\
Marmer/Batako/Terazo & 2640 & 1,298 \\
\hline (Sumber Satwiko, 2008$)$ & & \\
\hline
\end{tabular}

(Sumber: Satwiko, 2008)
Tabel 4. Faktor Radiasi Matahari (SF, $\left.\mathrm{W} / \mathrm{m}^{2}\right)$ untuk berbagai orientasi

\begin{tabular}{lccccccccc}
\hline \multirow{2}{*}{ Orientasi } & U & TL & T & TGR & S & BD & B & BL \\
\cline { 2 - 8 } & 130 & 113 & 112 & 97 & 97 & 176 & 243 & 211 \\
\hline
\end{tabular}

Berdasarkan data radiasi matahari di Jakarta.

Keterangan :

Rata-rata untuk seluruh orientasi SF $=147$

$\mathrm{U}=$ Utara

$\mathrm{TL}=$ Timur Laut

$\mathrm{T}=\mathrm{Timur}$

TGR $=$ Tenggara

$\mathrm{S}=$ Selatan

$\mathrm{BD}=$ Barat Daya

$\mathrm{B}=$ Barat

$\mathrm{BL}=$ Barat Laut

Koefisien peneduh dari sistem fenestrasi dapat diperoleh dengan cara mengkalikan besaran SC kaca dengan SC efektif dari kelengkapan peneduh luar, yaitu :

$S C=S C_{k} \times S C_{E f}$

Dimana :

$\mathrm{SC}=$ koefisien peneduh sistem fenestrasi

$\mathrm{SC}_{\mathrm{K}}=$ koefisien peneduh kaca

$\mathrm{SC}_{\mathrm{EF}}=$ koefisien peneduh efektif alat peneduh

Koefisien peneduh dari sistem fenestrasi dapat diperoleh dengan cara mengkalikan besaran SC kaca dengan SC efektif dari kelengkapan peneduh luar, yaitu :

\section{HASIL DAN PEMBAHASAN}

Lokasi penelitian dalam Analisa Hemat Energi ini adalah Gedung GPIB Kelapa Gading yang ada di jalan Janur Asri VII - VIII Blok QK / 15 - 16. No. 1. Berikut adalah data fisik bangunannya : 


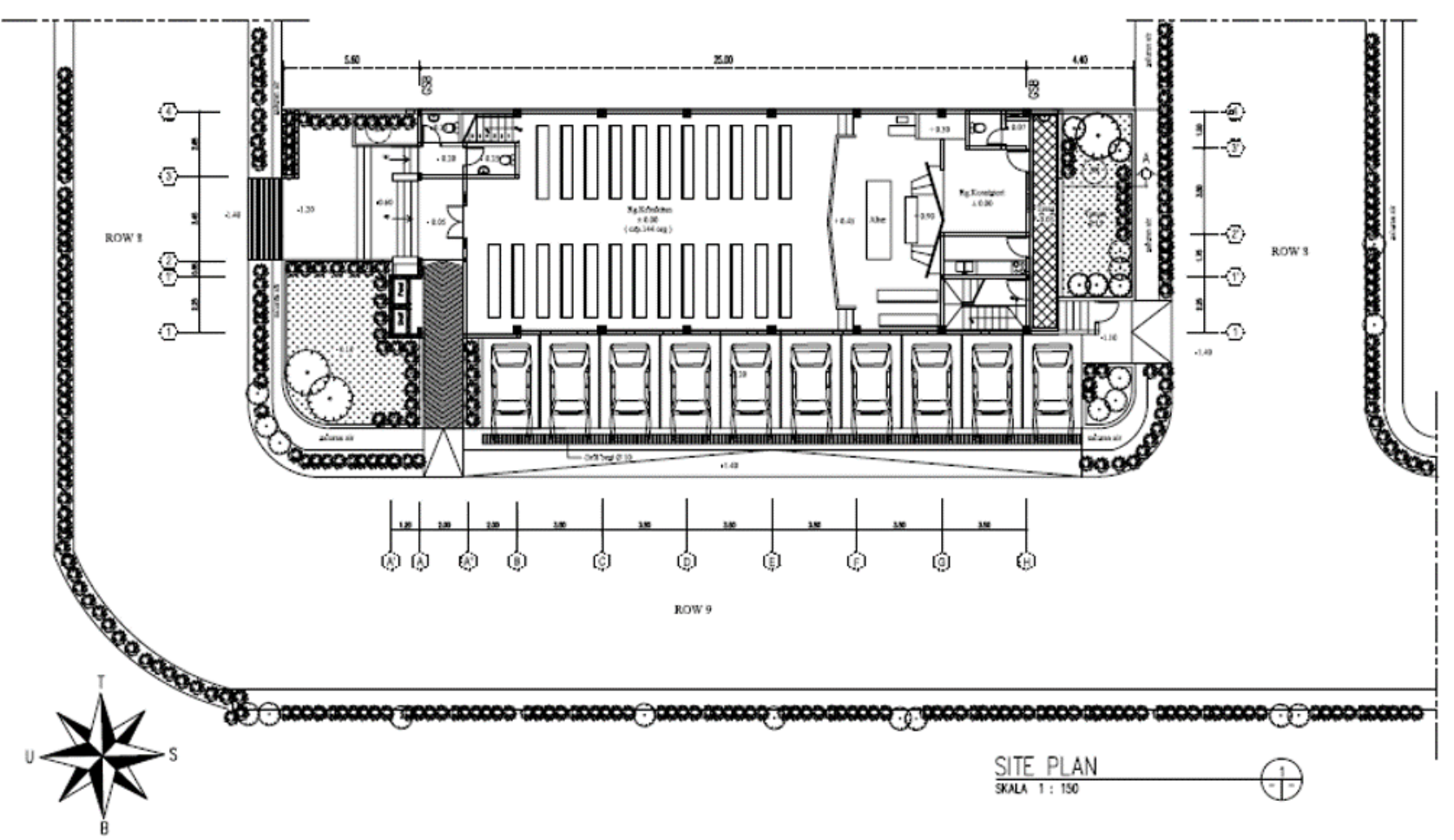

Gambar 1. Site Plan Gedung GPIB Kelapa Gading

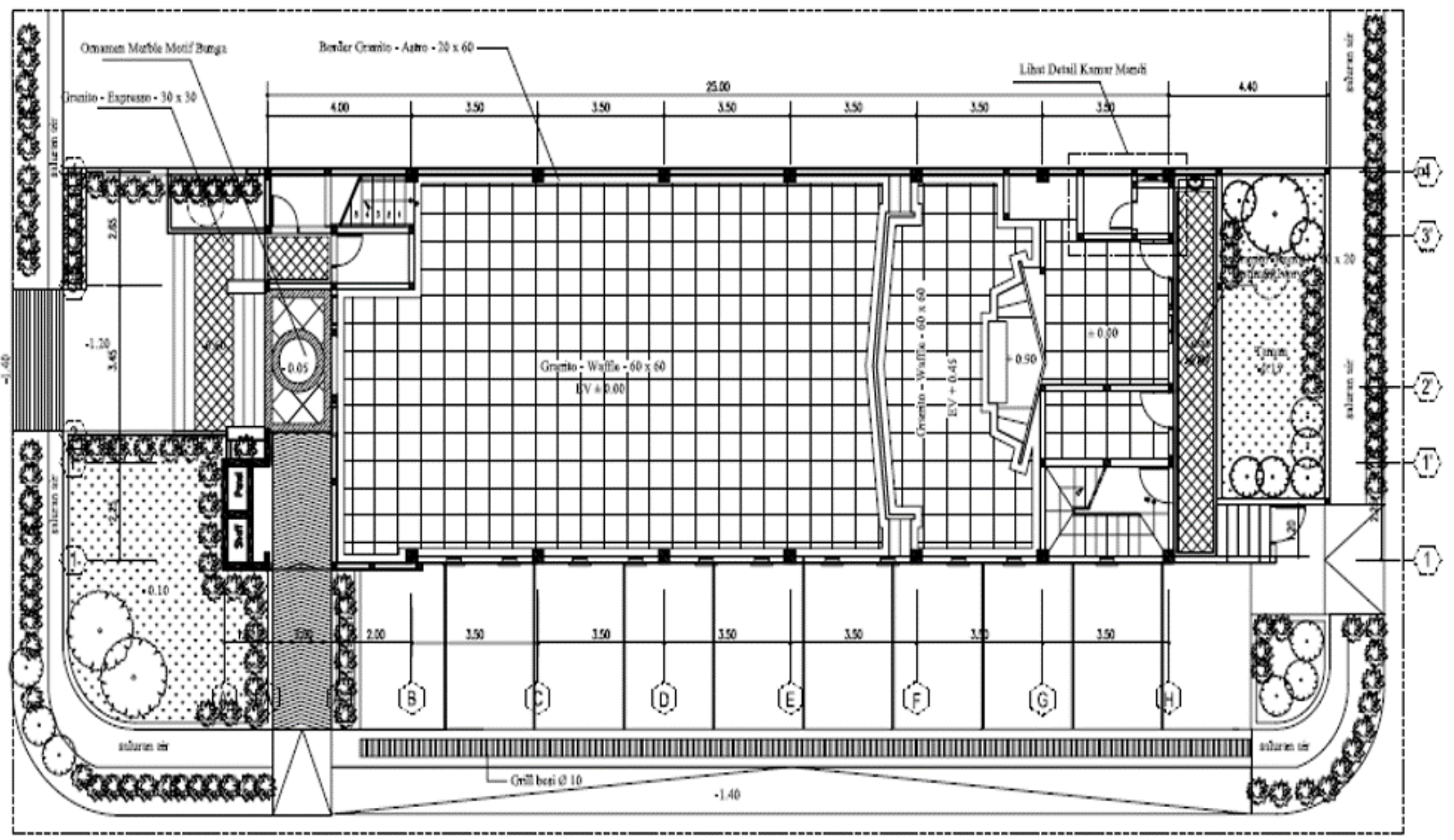

Gambar 2. Denah Lantai Dasar Gedung GPIB Kelapa Gading 

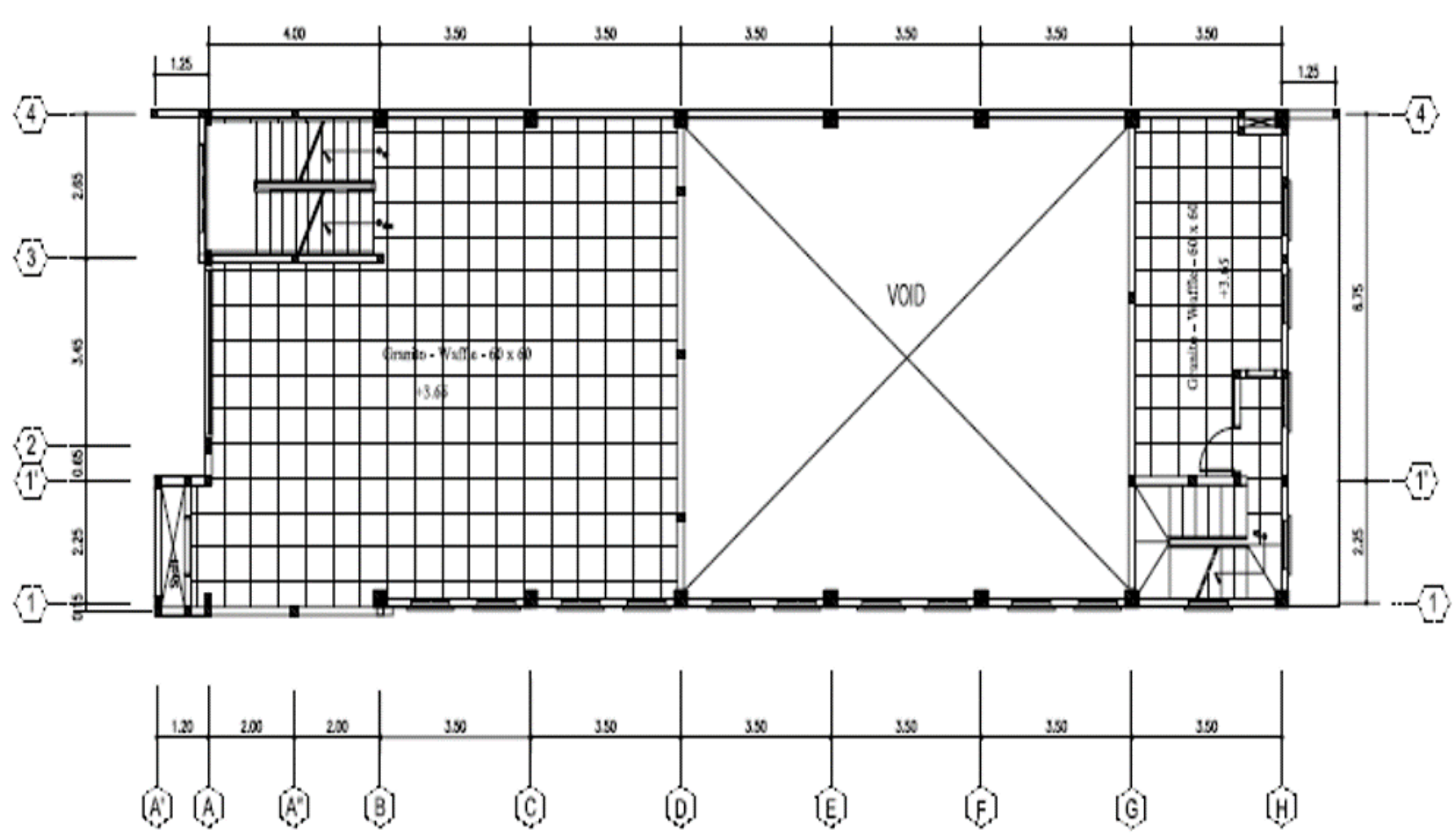

Gambar 3. Denah Lantai Mezanine Gedung GPIB Kelapa Gading
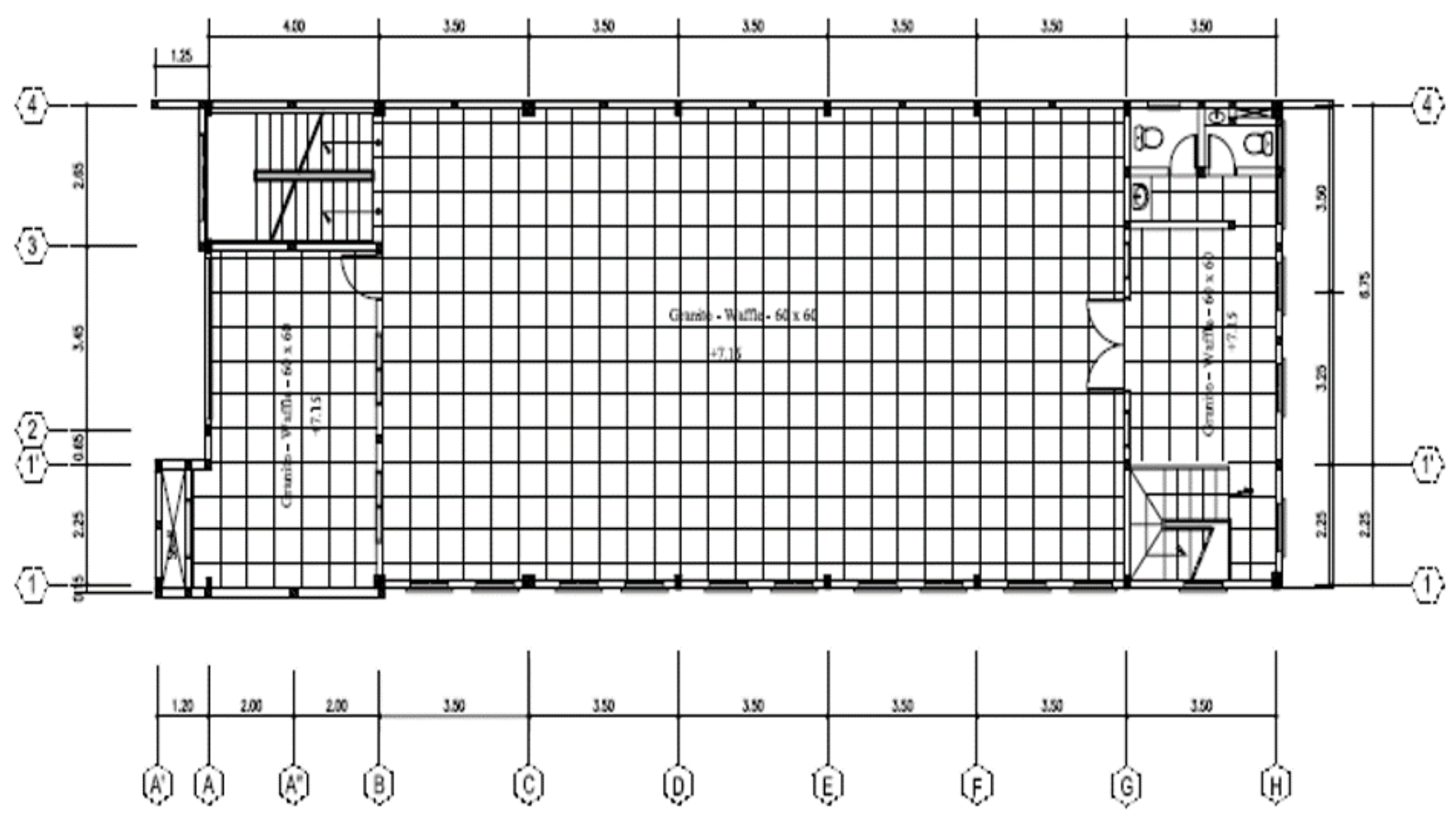

Gambar 4. Denah Lantai Dua Gedung GPIB Kelapa Gading 

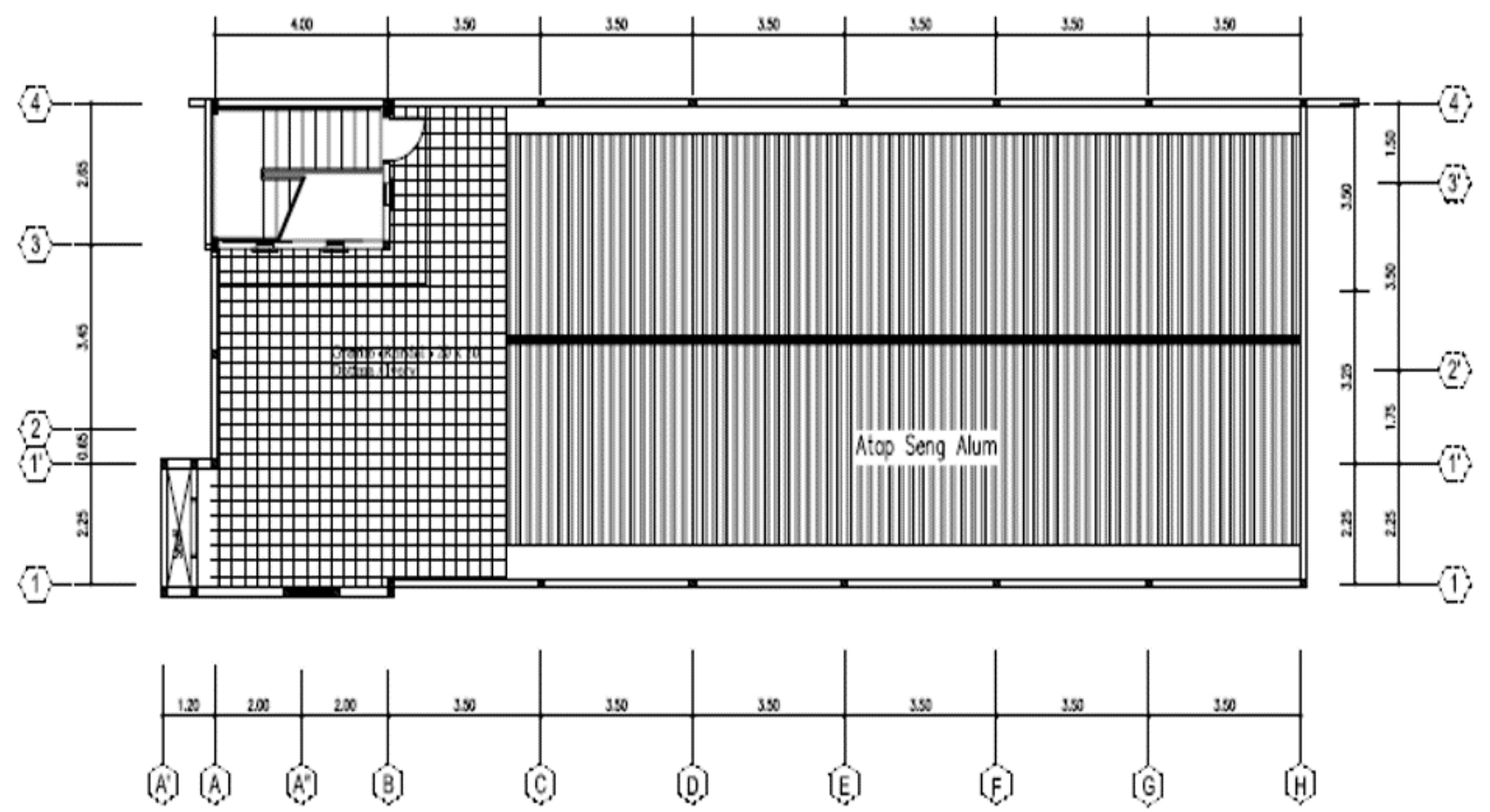

Gambar 5. Denah Top Floor Gedung GPIB Kelapa Gading

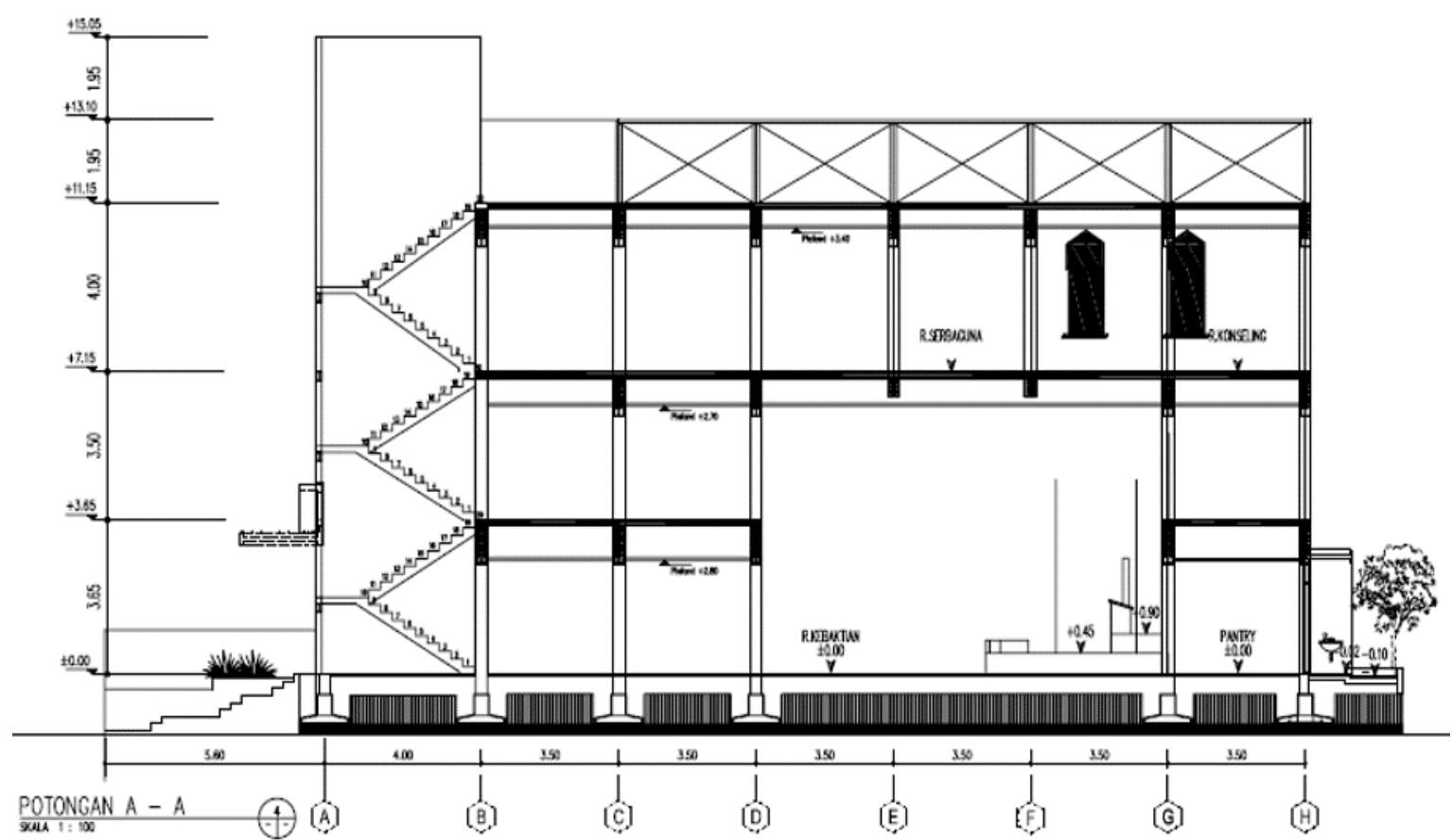

Gambar 6. Potongan Gedung GPIB Kelapa Gading 


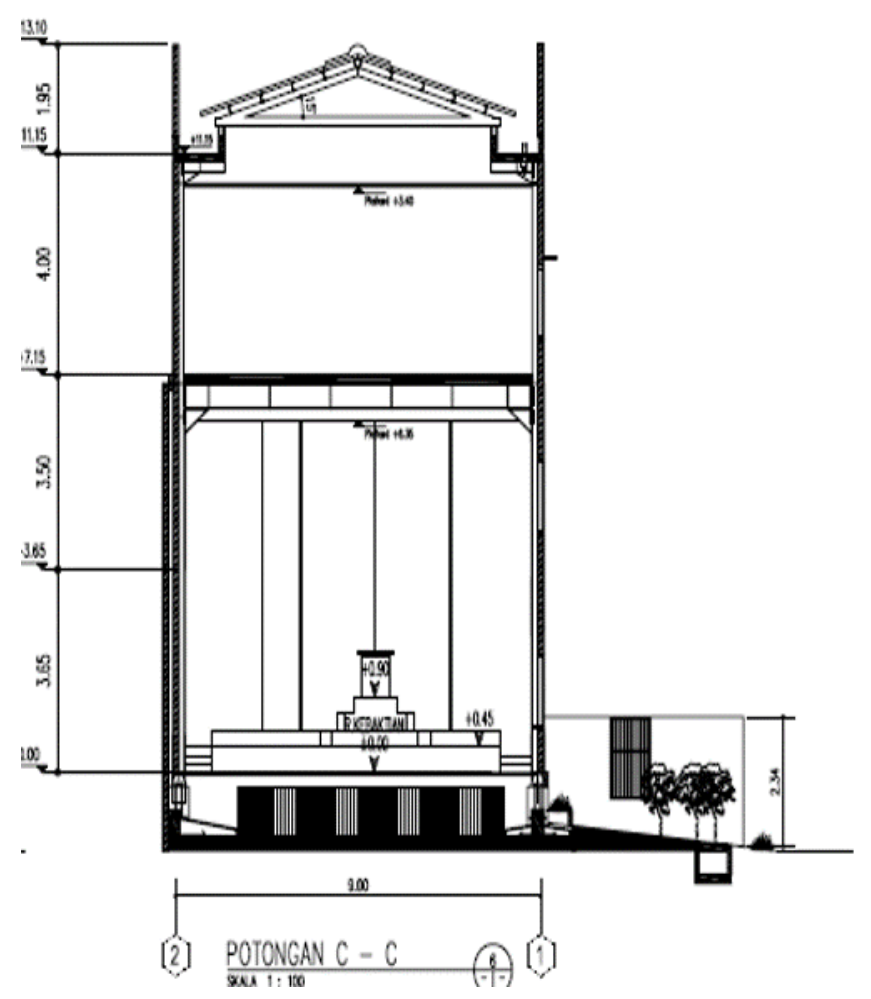

Gambar 7. Potongan Gedung GPIB Kelapa Gading
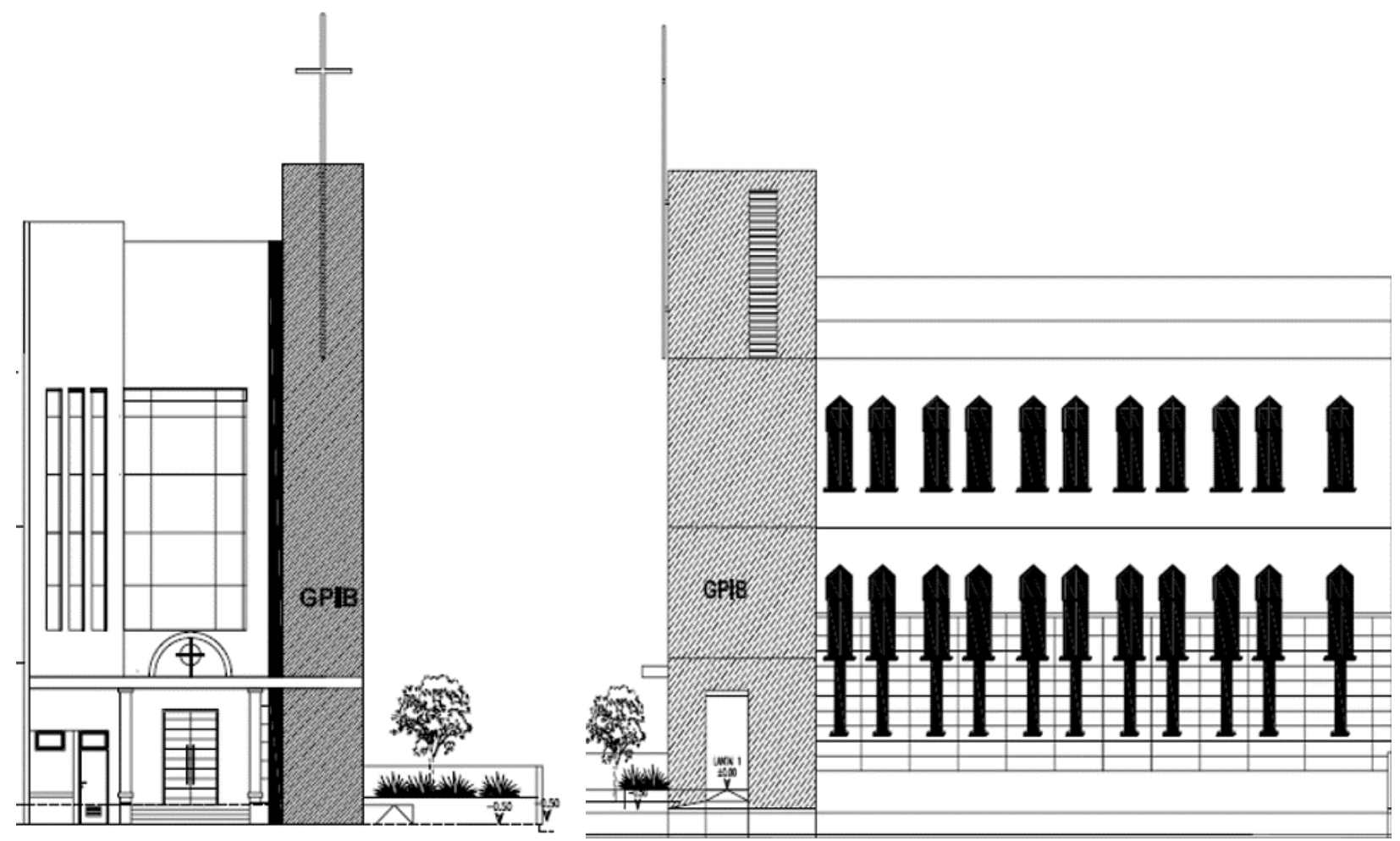

Gambar 8. Tampak Depan (Kiri) dan Tampak Samping (Kanan) Gedung GPIB Kelapa Gading 
Gambar 1-8, diketahui bangunan gedung GPIB dengan fungsi ibadah dan sosial memiliki data sebagai berikut : (1) Panjang bangunan yang akan dikondisikan adalah : 23,5 meter, (2) Lebar bangunan yang akan dikondisikan adalah : 9 meter, (3) Tinggi bangunan yang akan dikondisikan adalah 13,1 meter, (4) Finishing dinding luar bangunan adalah Cat Warna Abu-abu $(\alpha=0,88)$.

Penyelesaian dengan menghitung nilai $\mathrm{U}$, dimana $U_{w}$ :

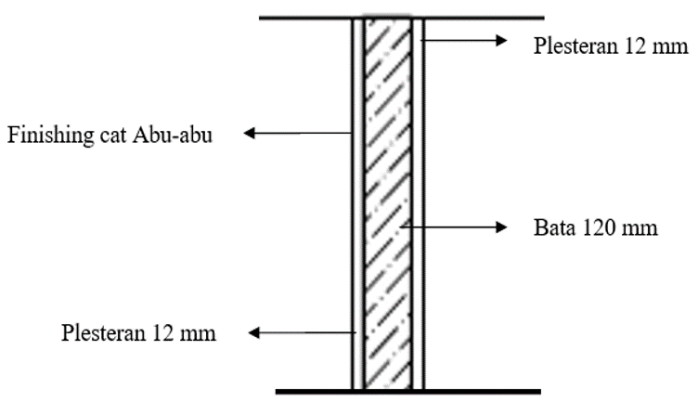

Gambar 9. Detail spesifikasi dinding

Tabel 5. Perhitungan Nila R Total Dinding

\begin{tabular}{lcc}
\hline \multicolumn{1}{c}{ Komponen } & $\mathbf{R}_{\mathbf{K}}=\boldsymbol{t} / \boldsymbol{k}$ & $\mathbf{R}$ \\
\hline Film udara luar & & 0,044 \\
Plesteran $12 \mathrm{~mm}$ & $0,012 / 0,533$ & 0,023 \\
Bata $120 \mathrm{~mm}$ & $0,120 / 0,807$ & 0,149 \\
Plesteran $12 \mathrm{~mm}$ & $0,012 / 0,533$ & 0,023 \\
Film udara dalam & & 0,120 \\
\hline \multicolumn{1}{c}{ R Total } & & $\mathbf{0 , 3 5 9}$ \\
\hline
\end{tabular}

$$
\begin{aligned}
& \begin{aligned}
\mathrm{U}_{\mathrm{w}} & =1 / \text { Rtotal } \\
& =1 / 0,359 \\
\mathbf{U}_{\mathbf{w}} & =\mathbf{2 , 7 8 6} \mathbf{~ W a t t} / \mathbf{m}^{2} . \mathbf{K}
\end{aligned} \\
& \text { Dimana } \mathrm{U}_{\mathrm{f}:}
\end{aligned}
$$

\begin{tabular}{|c|c|c|}
\hline Komponen & $\mathbf{R}_{\mathrm{K}}=\boldsymbol{t} / \boldsymbol{k}$ & $\mathbf{R}$ \\
\hline $\begin{array}{l}\text { Film udara luar } \\
\text { Kaca } 6 \mathrm{~mm} \\
\text { Film udara dalam }\end{array}$ & $0,006 / 1,053$ & $\begin{array}{l}0,044 \\
0,006 \\
0,120\end{array}$ \\
\hline R Total & & 0,170 \\
\hline \multicolumn{3}{|c|}{$\begin{aligned} \mathrm{Uf} & =1 / \text { Rtotal } \\
& =1 / 0,170 \\
\mathrm{Uf} & =5.882 \mathrm{Watt} / \mathrm{m} 2\end{aligned}$} \\
\hline $\begin{array}{l}\text { Menghitung nilai } \mathrm{TD}_{\mathrm{P}} \\
\text { 3erat dinding }=(156 \\
1568 \times 0,012) \\
=18,816+211,2+ \\
=248,832 \mathrm{~kg} / \mathrm{m}^{2} \sim T\end{array}$ & $\begin{array}{l}0,012)+(176 \\
816 \\
\mathbf{K}=\mathbf{1 0} \mathbf{K}\end{array}$ & $0,120)+$ \\
\hline
\end{tabular}

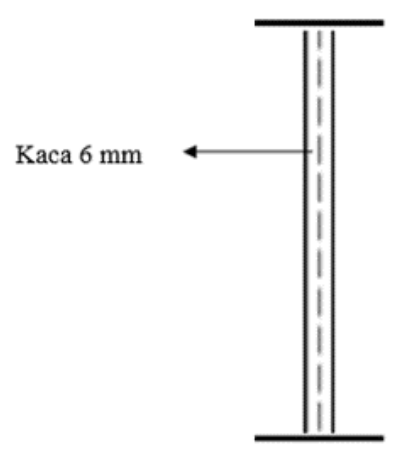

Gambar 10. Detail spesifikasi dinding
Tabel 6. Perhitungan Nila R Total Kaca

\section{Menghitung nilai WWR}

\section{WWR orientasi Utara}

Jendela yang ada pada sisi / fasad bagian utara gedung.
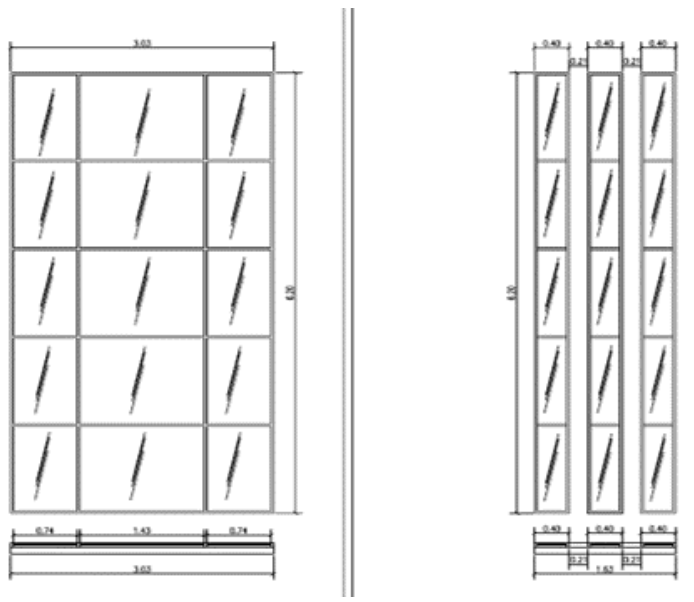

Gambar 11. Detail Jendela Utara

Jumlah luasan jendela secara keseluruhan adalah :

Type $1: 3,03$ x $6,20=\mathbf{1 8 , 7 8 6} \mathbf{~ m}^{\mathbf{2}}$

Type $2: 0,4 \times 3$ buah $=1,2 \times 6,20=\mathbf{7 , 4 4} \mathbf{~ m}^{2}$

Luasan bidang dinding secara keseluruhan adalah :

Untuk Type 1, luasan dinding adalah $=4,1 \mathrm{~m} \mathrm{x}$

$9,45 \mathrm{~m}=\mathbf{3 8 , 7 4 5} \mathbf{~ m}^{2}$

Sehingga WWR pada bidang tersebut adalah : $18,786 \mathrm{~m}^{2} / 38,745 \mathrm{~m}^{2}=\mathbf{0 , 4 8}$ 
Untuk Type 2, luasan dinding adalah $=2,65 \mathrm{~m} \mathrm{x}$ $9,45 \mathrm{~m}=\mathbf{2 5 , 0 4 2 5} \mathbf{~ m}^{2}$

Sehingga WWR pada bidang tersebut adalah : 7,44 $\mathrm{m}^{2} / 25,0425 \mathrm{~m}^{2}=\mathbf{0 , 2 9}$

\section{WWR orientasi Selatan}

Jendela yang ada pada sisi / fasad bagian selatan Gedung.
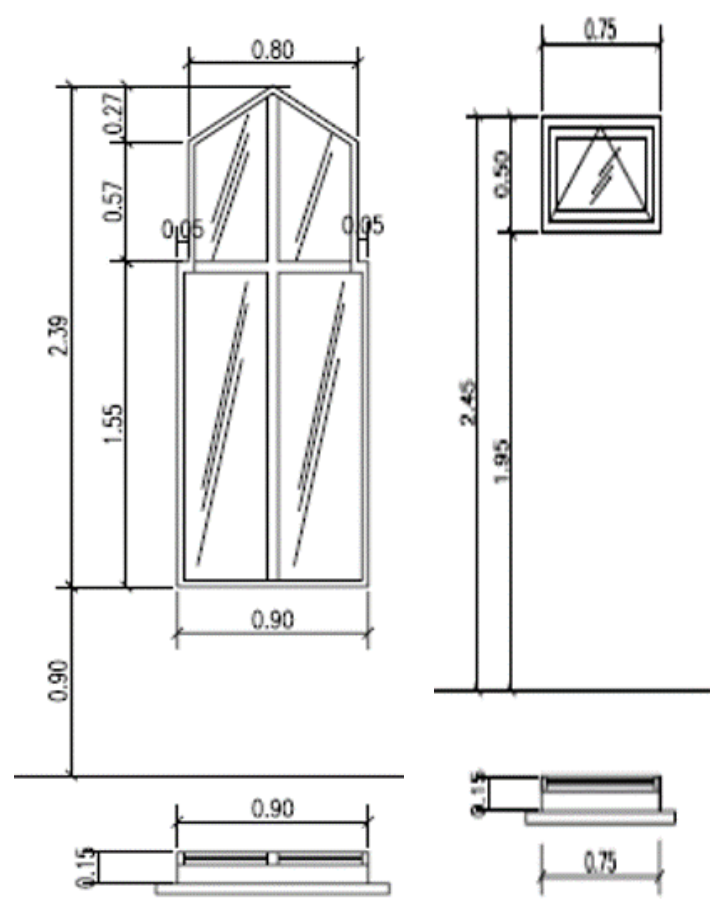

Gambar 12. Detail Jendela Selatan

Jumlah luasan jendela secara keseluruhan adalah :

Type $5 \mathrm{a}: 0,9 \times 4$ buah $=3,6 \times 2,39=8,604 \mathrm{~m} 2$ (untuk lantai 2)

Type $5 \mathrm{~b}: 0,9 \times 4$ buah $=3,6 \times 2,39=8,604 \mathrm{~m} 2$ (untuk lantai 3)

Type $6: 0,75 \times 0,50=0,375 \mathrm{~m} 2$

Untuk Type 5a, luasan dinding adalah $=3,50 \mathrm{~m} \mathrm{x}$ $9,0 \mathrm{~m}=31,50 \mathrm{~m} 2$. Sehingga WWR pada bidang tersebut adalah : 8,604 $\mathrm{m} 2 / 31,50 \mathrm{~m} 2=0,27$

Untuk Type $5 \mathrm{~b}$, luasan dinding adalah $=4,0 \mathrm{~m} \mathrm{x}$ $8,0 \mathrm{~m}=32,0 \mathrm{~m} 2$. Sehingga WWR pada bidang tersebut adalah : 8,604 $\mathrm{m} 2 / 32,0 \mathrm{~m} 2=0,269$

Untuk Type 6, luasan dinding adalah $=4,0 \mathrm{~m} \times 1,0$ $\mathrm{m}=4,0 \mathrm{~m} 2$. Sehingga WWR pada bidang tersebut adalah : $0,375 \mathrm{~m} 2 / 4,0 \mathrm{~m} 2=0,1$

\section{WWR orientasi Barat}
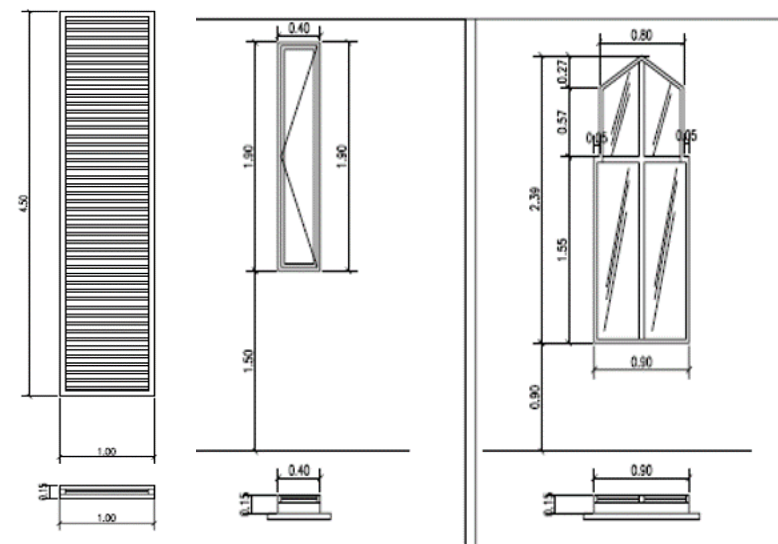

Gambar 13. Detail Jendela Barat

Jumlah luasan jendela secara keseluruhan adalah : Type $3: 1 \times 4,50=4,50 \mathrm{~m} 2$

Type $4: 0,4 \times 11$ buah $=4,4 \times 1,90=8,36 \mathrm{~m} 2$ Type $5 \mathrm{a}: 0,9 \times 11$ buah $=9,9 \times 2,39=23,661 \mathrm{~m} 2$ (untuk lantai 2)

Type $5 \mathrm{~b}: 0,9 \times 11$ buah $=9,9 \times 2,39=23,661 \mathrm{~m} 2$ (untuk lantai 3)

Untuk Type 3, luasan dinding adalah $=4,0 \mathrm{~m} \mathrm{x}$ $5,35 \mathrm{~m}=21,40 \mathrm{~m} 2$. Sehingga WWR pada bidang tersebut adalah : 4,50 $\mathrm{m} 2 / 21,40 \mathrm{~m} 2=0,21$

Untuk Type 4, luasan dinding adalah $=21,0 \mathrm{~m} \mathrm{x}$ $3,65 \mathrm{~m}=76,65 \mathrm{~m} 2$. Sehingga WWR pada bidang tersebut adalah : 8,36 $\mathrm{m} 2 / 76,65 \mathrm{~m} 2=0,11$

Untuk Type 5a, luasan dinding adalah $=21,0 \mathrm{~m} \mathrm{x}$ $3,50 \mathrm{~m}=73,50 \mathrm{~m}$. Sehingga WWR pada bidang tersebut adalah : $23,661 \mathrm{~m} 2 / 73,50 \mathrm{~m} 2=0,32$

Untuk Type $5 \mathrm{~b}$, luasan dinding adalah $=21,0 \mathrm{~m} \mathrm{x}$ $4,0 \mathrm{~m}=84,0 \mathrm{~m} 2$. Sehingga WWR pada bidang tersebut adalah : $23,661 \mathrm{~m} 2 / 84,0 \mathrm{~m} 2=0,28$

\section{Menghitung nilai SC}

\section{SC orientasi Utara}

$\left(S C_{K A C A}=0,5 ; I_{T}=508,01\right.$ (diambil dari penggunaan software Matahari)) :

Jendela Type $1: 3,03 \times 6,20=\mathbf{1 8 , 7 8 6} \mathbf{~ m}^{2}$

$$
\begin{aligned}
\mathrm{H} & =\mathrm{A} \times \mathrm{I}_{\mathrm{T}} \\
& =18,786 \times 508,01 \\
\mathbf{H} & =\mathbf{9 5 4 3 , 4 8} \\
\mathrm{SC}_{\mathrm{EF}} & =\mathrm{H} / \mathrm{A} \times \mathrm{I}_{\mathrm{T}} \\
& =9543,48 / 9543,48
\end{aligned}
$$


$\mathbf{S C}_{\mathbf{E F}}=\mathbf{1}$ (Tidak Terdapat Fenetrasi / Peneduh)

$\mathrm{SC}=\mathrm{SC}_{\mathrm{KACA}} \times \mathrm{SC}_{\mathrm{EF}}$

$$
=0,5 \times 1
$$

$\mathrm{SC}_{\mathrm{a}}=0,5$

Jendela Type $2: 0,4 \times 3$ buah $=1,2 \times 6,20=$ $7,44 \mathrm{~m}^{2}$

$\mathrm{H}=\mathrm{A} \times \mathrm{I}_{\mathrm{T}}$

$$
=7,44 \times 508,01
$$

$\mathrm{H}=\mathbf{3 7 7 9 , 5 9}$

$\mathrm{SC}_{\mathrm{EF}}=\mathrm{H} / \mathrm{AxI}$ $=3779,59 / 3779,59$

$\mathbf{S C}_{\mathbf{E F}}=\mathbf{1}$ (Tidak Terdapat Fenetrasi / Peneduh)

$\mathrm{SC}=\mathrm{SC}_{\mathrm{KACA}} \times \mathrm{SC}_{\mathrm{EF}}$ $=0,5 \times 1$

$\mathrm{SC}_{\mathrm{b}}=\mathbf{0 , 5}$

\section{SC orientasi Selatan}

$\left(S C_{K A C A}=0,5\right)$ :

Jendela Type $5 \mathrm{a}: 0,9 \times 4$ buah $=3,6 \times 2,39=$ $8,604 \mathrm{~m}^{2}$ (untuk lantai 2)

$$
\begin{aligned}
\mathrm{A}_{\mathrm{EK}} & =1,55 \times 0,90 \\
& =1,395 \mathrm{~m}^{2} \\
& =1,395 \times 4
\end{aligned}
$$

Total $\mathrm{A}_{\mathrm{EK}}=\mathbf{5 , 5 8} \mathbf{~ m}^{\mathbf{2}}$

$$
\begin{aligned}
\mathrm{G} & =\mathrm{A}_{\mathrm{EK}} / \mathrm{A} \\
& =5,58 / 8,604 \\
\mathbf{G} & =\mathbf{0 , 6 4 9}
\end{aligned}
$$

$$
\begin{aligned}
\mathrm{SC}_{\mathrm{EF}}= & \sum M\left(\mathrm{G}_{\mathrm{I}} \mathrm{I}_{\mathrm{L}}+\mathrm{I}_{\mathrm{D}}\right)+\sum J\left(\mathrm{G}_{\mathrm{I}} \mathrm{I}_{\mathrm{L}}+\mathrm{I}_{\mathrm{D}}\right)+\sum S \\
& \left(\mathrm{G}_{\mathrm{I}}+\mathrm{I}_{\mathrm{D}}\right)+\sum D\left(\mathrm{G}_{\mathrm{I}} \mathrm{I}_{\mathrm{L}}+\mathrm{I}_{\mathrm{D}}\right) / \\
= & \sum M(0,649 \times 0+180,34)+\sum J(0,649 \mathrm{x} \\
& 142,098+169,626)+\sum S(0,649 \times 0+ \\
& 180,52)+\sum D(0,649 \times 0+149,04) / \\
& 180,34+311,72+180,52+149,0 \\
= & 180,34+261,85+180,52+149,04 / 180,34 \\
& +311,72+180,52+149,04 \\
= & 771,75 / 821,62 \\
\mathbf{S C}_{\mathbf{E F}}= & \mathbf{0 , 9 4} \\
\mathrm{SC}= & \mathrm{SC}_{\mathrm{KACA}} \times \mathrm{SC}_{\mathrm{EF}} \\
= & 0,5 \times 0,94 \\
\mathbf{S C}= & \mathbf{0 , 4 7}
\end{aligned}
$$

Type $5 b: 0,9 \times 4$ buah $=3,6 \times 2,39=8,604 \mathrm{~m}^{2}$ (untuk lantai 3)

$$
\begin{aligned}
& \mathrm{A}_{\mathrm{EK}}=1,55 \times 0,90 \\
& =1,395 \mathrm{~m}^{2} \\
& =1,395 \times 4 \\
& \text { Total } A_{E K}=5,58 \mathbf{~ m}^{2} \\
& \mathrm{G}=\mathrm{A}_{\mathrm{EK}} / \mathrm{A} \\
& =5,58 / 8,604 \\
& \mathbf{G}=\mathbf{0 , 6 4 9}
\end{aligned}
$$

$$
\begin{aligned}
\mathrm{SC}_{\mathrm{EF}}= & \sum M\left(\mathrm{G}_{\mathrm{I}}+\mathrm{I}_{\mathrm{L}}\right)+\sum J\left(\mathrm{G}_{\mathrm{D}} \mathrm{I}_{\mathrm{L}}+\mathrm{I}_{\mathrm{D}}\right)+\sum S \\
& \left(\mathrm{G}_{\mathrm{I}}+\mathrm{I}_{\mathrm{D}}\right)+\sum D\left(\mathrm{G}_{\mathrm{L}}+\mathrm{I}_{\mathrm{D}}\right) / \sum M \mathrm{I}_{\mathrm{T}}+\sum J \mathrm{I}_{\mathrm{T}} \\
& +\sum S \mathrm{I}_{\mathrm{T}}+\sum D \mathrm{I}_{\mathrm{T}} \\
= & \sum M(0,649 \times 0+180,34)+\sum J(0,649 \mathrm{x} \\
& 142,098+169,626)+ \\
& \sum S(0,649 \times 0+180,52)+\sum D(0,649 \times 0+ \\
& 149,04) / \quad 180,34+311,72+180,52 \\
& +149,04 \\
= & 180,34+261,85+180,52+149,04+180,34 \\
& +311,72+180,52+149,04 \\
= & 771,75 / 821,62 \\
\mathbf{S C}_{\mathrm{EF}}= & \mathbf{0 , 9 4} \\
\mathbf{S C}= & \mathrm{SC}_{\mathrm{KACA}} \times \mathrm{SC}_{\mathrm{EF}} \\
= & 0,5 \times 0,94 \\
\mathbf{S C}= & \mathbf{0 , 4 7}
\end{aligned}
$$

Jendela Type $6: 0,75 \times 0,50=\mathbf{0 , 3 7 5} \mathbf{~ m}^{2}$ $\left(S C_{K A C A}=0,5 ; I_{T}=311,72\right.$ (diambil dari penggunaan software Matahari)) :

$$
\begin{aligned}
\mathrm{H} & =\mathrm{A} \times \mathrm{I}_{\mathrm{T}} \\
& =0,375 \times 311,72 \\
\mathbf{H} & =\mathbf{1 1 6 , 8 9 5} \\
\mathrm{SC}_{\mathrm{EF}} & =\mathrm{H} / \mathrm{A} \times \mathrm{I}_{\mathrm{T}} \\
& =116,895 / 116,895
\end{aligned}
$$

$\mathbf{S C}_{\mathbf{E F}}=\mathbf{1}$ (Tidak Terdapat Fenetrasi / Peneduh)

$$
\begin{aligned}
\mathrm{SC} & =\mathrm{SC}_{\mathrm{KACA}} \times \mathrm{SC}_{\mathrm{EF}} \\
& =0,5 \times 1 \\
\mathbf{S C} & =\mathbf{0 , 5}
\end{aligned}
$$

\section{SC orientasi Barat}

Jendela Type $4: 0,4 \times 11$ buah $=4,4 \times 1,90=$ $8,36 \mathbf{~ m}^{2}$

( $S C_{K A C A}=0,5 ; I_{T}=180,73$ (diambil dari penggunaan software Matahari)) :

$$
\begin{aligned}
\mathrm{H} & =\mathrm{A} \times \mathrm{I}_{\mathrm{T}} \\
& =8,36 \times 180,73 \\
\mathbf{H} & =\mathbf{1 5 1 0 , 9 0 3} \\
\mathrm{SC}_{\mathrm{EF}} & =\mathrm{H} / \mathrm{A} \times \mathrm{I}_{\mathrm{T}} \\
& =1510,903 / 1510,903 \\
\mathbf{S C}_{\mathrm{EF}} & =\mathbf{1} \text { (Tidak Terdapat Fenetrasi / Peneduh) } \\
\mathrm{SC} & =\mathrm{SC}_{\mathrm{KACA}} \times \mathrm{SC}_{\mathrm{EF}} \\
& =0,5 \times 1 \\
\mathbf{S C} & =\mathbf{0 , 5}
\end{aligned}
$$

Jendela $5 \mathrm{a}: 0,9 \times 11$ buah $=9,9 \times 2,39=23,661$ $\mathrm{m}^{2}$ (untuk lantai 2)

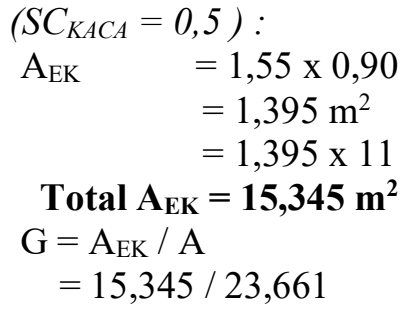




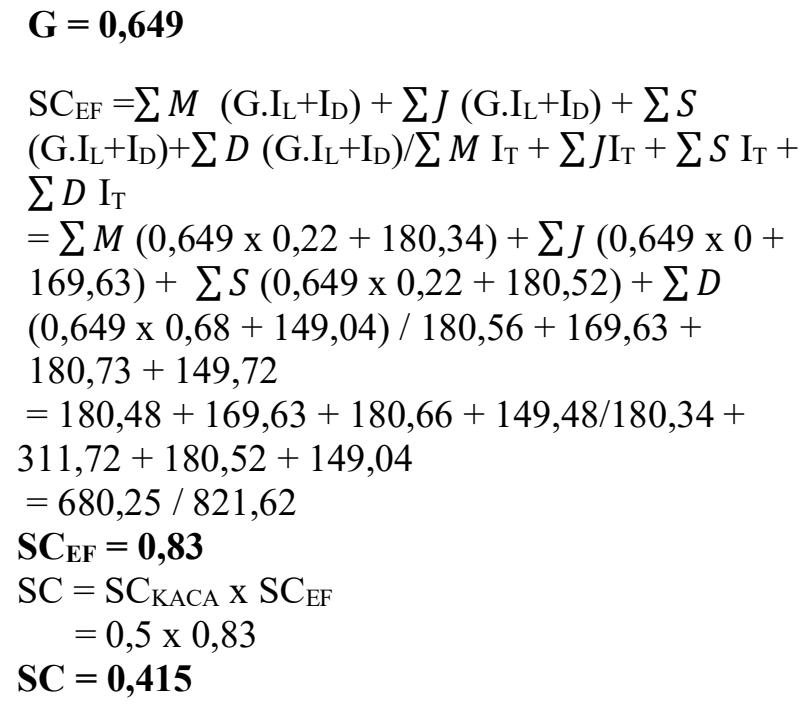

Jendela $5 b: 0,9 \times 11$ buah $=9,9 \times 2,39=23,661$ $\mathrm{m}^{2}$ (untuk lantai 3)

$\left(S C_{K A C A}=0,5\right)$ :

$\begin{aligned} \mathrm{A}_{\mathrm{EK}} & =1,55 \times 0,90 \\ & =1,395 \mathrm{~m}^{2} \\ & =1,395 \times 11\end{aligned}$

Total $A_{E K}=15,345$ m $^{2}$

$\mathrm{G}=\mathrm{A}_{\mathrm{EK}} / \mathrm{A}$

$=15,345 / 23,661$

$\mathbf{G}=\mathbf{0 , 6 4 9}$

$\mathrm{SC}_{\mathrm{EF}}=\sum M\left(\mathrm{G} . \mathrm{I}_{\mathrm{L}}+\mathrm{I}_{\mathrm{D}}\right)+\sum J\left(\mathrm{G} . \mathrm{I}_{\mathrm{L}}+\mathrm{I}_{\mathrm{D}}\right)+\sum S$

$\left(\mathrm{G}^{\mathrm{I}} \mathrm{I}_{\mathrm{L}}+\mathrm{I}_{\mathrm{D}}\right)+\sum D\left(\mathrm{G} . \mathrm{I}_{\mathrm{L}}+\mathrm{I}_{\mathrm{D}}\right) /$

$\sum M \mathrm{I}_{\mathrm{T}}+\sum J \mathrm{I}_{\mathrm{T}}+\sum S \mathrm{I}_{\mathrm{T}}+\sum D \mathrm{I}_{\mathrm{T}}$

$=\sum M(0,649 \times 0,22+180,34)+\sum J(0,649 \times 0+$ $169,63)+\sum S(0,649 \times 0,22+180,52)+\sum D$ $(0,649 \times 0,68+149,04) / 180,56+169,63+$ $180,73+149,72$

$=180,48+169,63+180,66+149,48 / 180,34+$

$311,72+180,52+149,04$

$=680,25 / 821,62$

$\mathbf{S C}_{\mathrm{EF}}=\mathbf{0 , 8 3}$

$\mathrm{SC}=\mathrm{SC}_{\mathrm{KACA}} \times \mathrm{SC}_{\mathrm{EF}}$

$=0,5 \times 0,83$

$\mathbf{S C}=\mathbf{0 , 4 1 5}$

\section{Menghitung nilai OTTV pada orientasi bangunan}

\section{OTTV orientasi Utara}

$=\alpha\left[\mathrm{U}_{\mathrm{w}} \mathrm{X}\left(1-\mathrm{WWR}_{\mathrm{a}}\right)\right] \mathrm{x} \mathrm{TD}_{\mathrm{EK}}+\left(\mathrm{SC}_{\mathrm{a}} \mathrm{XWWR} \mathrm{W}\right.$ $\mathrm{SF})+\left(\mathrm{U}_{\mathrm{f}} \mathrm{x} \mathrm{WWR}_{\mathrm{a}} \mathrm{x} \Delta \mathrm{T}\right)$

$=0,88[2,786 \times(1-0,48)] \times 10+(0,5 \times 0,48 \times$

$130)+(5,882 \times 0,48 \times 5)$

$=0,88[2,786 \times 0,52] \times 10+31,2+14,1168$

$=0,88 \times 1,44872 \times 10+31,2+14,1168$

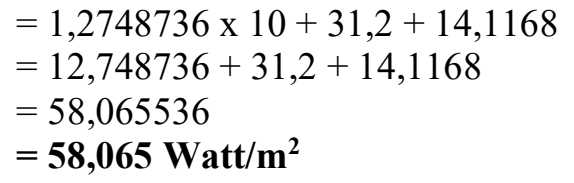

\section{OTTV orientasi Utara}

$=\alpha\left[\mathrm{U}_{\mathrm{w}} \mathrm{x}\left(1-\mathrm{WWR}_{\mathrm{b}}\right)\right] \mathrm{x} \mathrm{TD}_{\mathrm{EK}}+\left(\mathrm{SC}_{\mathrm{b}} \mathrm{x} \mathrm{WWR}_{\mathrm{b}} \mathrm{X}\right.$ $\mathrm{SF})+\left(\mathrm{U}_{\mathrm{f}} \mathrm{x} W W R_{\mathrm{b}} \mathrm{x} \Delta \mathrm{T}\right)$

$=0,88[2,786 \times(1-0,29)] \times 10+(0,5 \times 0,29 \times$

$130)+(5,882 \times 0,29 \times 5)$

$=0,88[2,786 \times 0,71] \times 10+18,85+8,5289$

$=0,88 \times 1,97806 \times 10+18,85+8,5289$

$=1,7406928 \times 10+18,85+8,5289$

$=17,406928+18,85+8,5289$

$=44,785828$

$=44,785 \mathrm{Watt} / \mathrm{m}^{2}$

\section{OTTV orientasi Selatan}

$=\alpha\left[\mathrm{U}_{\mathrm{w}} \mathrm{x}\left(1-\mathrm{WWR}_{\mathrm{a}}\right)\right] \mathrm{x} \mathrm{TD}_{\mathrm{EK}}+\left(\mathrm{SC}_{\mathrm{a}} \mathrm{x} \mathrm{WWR}_{\mathrm{a}} \mathrm{x}\right.$

$\mathrm{SF})+\left(\mathrm{U}_{\mathrm{f}} \times \mathrm{WWR}_{\mathrm{a}} \times \Delta \mathrm{T}\right)$

$=0,88[2,786 \times(1-0,27)] \times 10+(0,47 \times 0,27 \times$

$97)+(5,882 \times 0,27 \times 5)$

$=0,88[2,786 \times 0,73] \times 10+12,3093+7,9407$

$=0,88 \times 2,03378 \times 10+12,3093+7,9407$

$=1,7897264 \times 10+12,3093+7,9407$

$=17,897264+12,3093+7,9407$

$=22,0397264$

$=22,040 \mathrm{Watt} / \mathrm{m}^{2}$

\section{OTTV orientasi Selatan}

$=\alpha\left[\mathrm{U}_{\mathrm{w}} \mathrm{x}\left(1-\mathrm{WWR}_{\mathrm{b}}\right)\right] \mathrm{x} \mathrm{TD}_{\mathrm{EK}}+\left(\mathrm{SC}_{\mathrm{b}} \mathrm{x} \mathrm{WWR}_{\mathrm{b}} \mathrm{x}\right.$ $\mathrm{SF})+\left(\mathrm{U}_{\mathrm{f}} \times \mathrm{WWR}_{\mathrm{b}} \times \Delta \mathrm{T}\right)$

$=0,88[2,786 \times(1-0,269)] \times 10+(0,47 \times 0,269 \times$ $97)+(5,882 \times 0,269 \times 5)$

$=0,88[2,786 \times 0,731] \times 10+12,26371+7,91129$

$=0,88 \times 2,036566 \times 10+12,26371+7,91129$

$=1,79217808 \times 10+12,26371+7,91129$

$=17,9217808+12,26371+7,91129$

$=38,0967808$

$=38,097 \mathrm{Watt} / \mathrm{m}^{2}$

\section{OTTV orientasi Selatan}

$=\alpha\left[\mathrm{U}_{\mathrm{w}} \mathrm{x}\left(1-\mathrm{WWR}_{\mathrm{c}}\right)\right] \mathrm{x} \mathrm{TD}_{\mathrm{EK}}+\left(\mathrm{SC}_{\mathrm{c}} \mathrm{xWWR} \mathrm{W}\right.$ $\mathrm{SF})+\left(\mathrm{U}_{\mathrm{f}} \times \mathrm{WWR}_{\mathrm{c}} \times \Delta \mathrm{T}\right)$

$=0,88[2,786 \times(1-0,1)] \times 10+(0,5 \times 0,1 \times 97)+$ $(5,882 \times 0,1 \times 5)$

$=0,88[2,786 \times 0,9] \times 10+4,85+2,941$

$=0,88 \times 2,5074 \times 10+4,85+2,941$

$=2,206512 \times 10+4,85+2,941$

$=22,06512+4,85+2,941$

$=29,85612$

$=29,856 \mathrm{Watt} / \mathrm{m}^{2}$ 


\section{OTTV orientasi Timur}

$=\alpha\left[\mathrm{U}_{\mathrm{W}} \mathrm{x}(1-\mathrm{WWR})\right] \mathrm{x} \mathrm{TD}_{\mathrm{EK}}+(\mathrm{SC} \mathrm{x}$ WWR $\mathrm{x}$

$\mathrm{SF})+\left(\mathrm{U}_{\mathrm{f}} \times \mathrm{WWR} \times \Delta \mathrm{T}\right)$

$=0,88[2,786 \times(1-0)] \times 10+(0 \times 0 \times 112)+$

$(5,882 \times 0 \times 5)$

$=0,88[2,786 \times 1] \times 10+0+0$

$=0,88 \times 2,786 \times 10+0+0$

$=2,45168 \times 10+0+0$

$=24,5168+0+0$

$=24,5168$

$=\mathbf{2 4 , 5 1 7} \mathrm{Watt} / \mathrm{m}^{2}$

\section{OTTV orientasi Barat}

$=\alpha\left[\mathrm{U}_{\mathrm{w}} \mathrm{x}\left(1-\mathrm{WWR}_{\mathrm{a}}\right)\right] \mathrm{x} \mathrm{TD}_{\mathrm{EK}}+\left(\mathrm{SC}_{\mathrm{a}} \mathrm{x} \mathrm{WWR}_{\mathrm{a}} \mathrm{x}\right.$ $\mathrm{SF})+\left(\mathrm{U}_{\mathrm{f}} \times \mathrm{WWR}_{\mathrm{a}} \times \Delta \mathrm{T}\right)$

$=0,88[2,786 \times(1-0,21)] \times 10+(0 \times 0,21 \times 243)$

$+(5,882 \times 0,21 \times 5)$

$=0,88[2,786 \times 0,79] \times 10+0+6,1761$

$=0,88 \times 2,20094 \times 10+0+6,1761$

$=1,9368272 \times 10+0+6,1761$

$=19,368272+0+6,1761$

$=8,1129272$

$=8,113 \mathrm{Watt} / \mathrm{m}^{2}$

\section{OTTV orientasi Barat}

$=\alpha\left[\mathrm{U}_{\mathrm{w}} \mathrm{X}\left(1-\mathrm{WWR}_{\mathrm{b}}\right)\right] \mathrm{x} \mathrm{TD}_{\mathrm{EK}}+\left(\mathrm{SC}_{\mathrm{b}} \mathrm{X} \mathrm{WWR}_{\mathrm{b}} \mathrm{x}\right.$

$\mathrm{SF})+\left(\mathrm{U}_{\mathrm{f}} \times \mathrm{WWR}_{\mathrm{b}} \times \Delta \mathrm{T}\right)$

$=0,88[2,786 \times(1-0,11)] \times 10+(0,5 \times 0,11 \times$

$243)+(5,882 \times 0,11 \times 5)$

$=0,88[2,786 \times 0,89] \times 10+13,365+3,2351$

$=0,88 \times 2,47954 \times 10+13,365+3,2351$

$=2,1819952 \times 10+13,365+3,2351$

$=21,819952+13,365+3,2351$

$=38,420052$

$=38,420 \mathrm{Watt} / \mathrm{m}^{2}$

\section{OTTV orientasi Barat}

$=\alpha\left[\mathrm{U}_{\mathrm{w}} \mathrm{x}\left(1-\mathrm{WWR}_{\mathrm{c}}\right)\right] \mathrm{x} \mathrm{TD}_{\mathrm{EK}}+\left(\mathrm{SC}_{\mathrm{c}} \mathrm{x} \mathrm{WWR}_{\mathrm{c}} \mathrm{x}\right.$ $\mathrm{SF})+\left(\mathrm{U}_{\mathrm{f}} \times \mathrm{WWR}_{\mathrm{c}} \mathrm{x} \Delta \mathrm{T}\right)$

$=0,88[2,786 \times(1-0,32)] \times 10+(0,415 \times 0,32 \times$

$243)+(5,882 \times 0,32 \times 5)$

$=0,88[2,786 \times 0,68] \times 10+32,2704+9,4112$

$=0,88 \times 1,89448 \times 10+32,2704+9,4112$

$=1,6671424 \times 10+32,2704+9,4112$

$=16,671424+32,2704+9,4112$

$=58,353024$

$=58,353 \mathrm{Watt} / \mathrm{m}^{2}$

\section{OTTV orientasi Barat ${ }_{d}$}

$=\alpha\left[\mathrm{U}_{\mathrm{w}} \mathrm{x}\left(1-\mathrm{WWR}_{\mathrm{d}}\right)\right] \mathrm{x} \mathrm{TD}_{\mathrm{EK}}+\left(\mathrm{SC}_{\mathrm{d}} \mathrm{x} \mathrm{WWR}_{\mathrm{d}} \mathrm{x}\right.$ $\mathrm{SF})+\left(\mathrm{U}_{\mathrm{f}} \times \mathrm{WWR}_{\mathrm{d}} \mathrm{x} \Delta \mathrm{T}\right)$
$=0,88[2,786 \times(1-0,28)] \times 10+(0,415 \times 0,28 \times$

$243)+(5,882 \times 0,28 \times 5)$

$=0,88[2,786 \times 0,72] \times 10+28,2366+8,2348$

$=0,88 \times 2,00592 \times 10+28,2366+8,2348$

$=1,7652096 \times 10+28,2366+8,2348$

$=17,652096+28,2366+8,2348$

$=54,123496$

$=\mathbf{5 4 , 1 2 3 ~ W a t t} / \mathrm{m}^{2}$

\section{Menghitung nilai OTTV seluruh selubung bangunan}

OTTV $=\left(A_{\text {Utara }} \mathrm{x}\left(\right.\right.$ OTTV $\left.\left._{\mathrm{a}}+\mathrm{OTTV}_{\mathrm{b}}\right)\right)+\left(\mathrm{A}_{\text {Selatan }} \mathrm{x}\right.$ $\left(\right.$ OTTV $\left.\left._{\mathrm{a}}+\mathrm{OTTV}_{\mathrm{b}}+\mathrm{OTTV}_{\mathrm{c}}\right)\right)+\left(\mathrm{A}_{\text {Timur }} \mathrm{x}\right.$ OTTV $)+$ $\left(A_{\text {Barat }} \mathrm{x}\left(\mathrm{OTTV}_{\mathrm{a}}+\mathrm{OTTV}_{\mathrm{b}}+\mathrm{OTTV}_{\mathrm{c}}+\mathrm{OTTV}_{\mathrm{d}}\right)\right) /$

$\mathrm{A}_{\text {Utara }}+\mathrm{A}_{\text {Selatan }}+\mathrm{A}_{\text {Timur }}+\mathrm{A}_{\text {Barat }}$

$=\left(117,9 \mathrm{~m}^{2} \mathrm{x}(58,065+44,785)\right)+\left(117,9 \mathrm{~m}^{2} \mathrm{x}\right.$ $(22,040+38,097+29,856))+\left(343,22 \mathrm{~m}^{2} \mathrm{x}\right.$ $24,517)+\left(343,22 \mathrm{~m}^{2} \mathrm{x}(8,113+38,420+58,353\right.$ $+54,123)) / 117,9 \mathrm{~m}^{2}+117,9 \mathrm{~m}^{2}+343,22 \mathrm{~m}^{2}+$ $343,22 \mathrm{~m}^{2}$

$=\left(117,9 \mathrm{~m}^{2} \times 102,85\right)+\left(117,9 \mathrm{~m}^{2} \times 89,993\right)+$ $\left(343,22 \mathrm{~m}^{2} \times 24,517\right)+\left(343,22 \mathrm{~m}^{2} \times 159,009\right) /$ $117,9 \mathrm{~m}^{2}+117,9 \mathrm{~m}^{2}+343,22 \mathrm{~m}^{2}+343,22 \mathrm{~m}^{2}=$ $12126,015+10610,1747+8414,72474+$

$54575,06898 / 117,9 \mathrm{~m}^{2}+117,9 \mathrm{~m}^{2}+343,22 \mathrm{~m}^{2}+$ $343,22 \mathrm{~m}^{2}$

$=85725,98342 \mathrm{Watt} / 922,24 \mathrm{~m}^{2}$

$=92,95409375 \mathrm{Watt} / \mathrm{m}^{2}$

OTTV $=92,954 \mathrm{Watt} / \mathrm{m}^{2}$

\section{KESIMPULAN DAN SARAN}

Adapun kesimpulan dari penelitian ini adalah (1) Pada umumnya, Bangunan GPIB Kelapa Gading ini memiliki banyak jendela yang besar-besar dan jendela tersebut pada umumnya tidak memiliki fenetrasi sinar matahari yang mengakibatkan radiasi langsung = radiasi total, (2) OTTV tiap-tiap orientasi ada beragam yakni di bawah $45 \mathrm{watt} / \mathrm{m}^{2}$ (jumlahnya sangat besar), olehnya itu total OTTV keseluruhan selubung bangunan jauh di atas 45 watt $/ \mathrm{m}^{2}$, (3) Bangunan GPIB Kelapa Gading perlu dikontrol ulang terhadap desain dan kenyamanan bangunannya, karena banyaknya bukaan (jendela) yang ada pada sisi barat bangunan dan pada sisi utara bangunan terdapat jendela yang sangat Panjang (menerus) sehingga mengakibatkan panas /radiasi matahari yang diserap oleh bangunan sangat jauh dari standar yang ditetapkan oleh SNI 03-6989-2000. 


\section{DAFTAR PUSTAKA}

[1] Nasional BS (2000) Konservasi energi selubung bangunan pada bangunan gedung. SNI 03-6389-2000, Jakarta, Indonesia.

[2] Loekita S (2006) Analisis Konservasi Energi Melalui Selubung Bangunan. Civil Engineering Dimension Vol. 8, No. 2: hal. pp. 93-98.

[3] Sujatmiko W (2010) Studi Peluang Penghematan Pemakaian Energi pada Gedung Sekretariat Jenderal Pekerjaan Umum. Jurnal Permukiman Vol. 5, No. 3: hal. 124-131.

[4] Setiani AN, Harani AR, Riskiyanto R (2018) PERHITUNGAN OVERALL THERMAL TRANSFER VALUE (OTTV) PADA SELUBUNG BANGUNAN. Arsir Vol. 1, No. 2: hal. 100-109.

[5] Satwiko P (2008) Fisika Bangunan. Yogyakarta: Andi.

[6] Sangkertadi (2006) Fisika Bangunan untuk Mahasiswa Teknik, Arsitektur dan Praktisi. Bogor: Pustaka Wirausaha Muda. 